\title{
Smooth Muscle Neoplasm
}

National Cancer Institute

\section{Source}

National Cancer Institute. Smooth Muscle Neoplasm. NCI Thesaurus. Code C3751.

A benign or malignant myomatous neoplasm arising from smooth muscle. 